\title{
Análise das alterações do uso e cobertura do solo no município de Centenário-RS com o auxílio do Sensoriamento Remoto, no período de 1995-2014
}

\author{
Analysis of land use and land cover changes in the municipality of Centenario, RS \\ with the help of remote sensing in the period 1995-2014
}

\author{
Gisele carla may e Janete Teresinha Reis \\ Universidade Federal de Santa Maria, RS, Brasil \\ gisa_may1004@hotmail.com; reis.janete@gmail.com
}

\begin{abstract}
Resumo
O presente estudo objetivou analisar as mudanças no uso e cobertura do solo, a partir de imagens Landsat, para verificar a expansão ou retração agrícola no município de Centenário, $R S$, no período de 1995-2014. Foram utilizadas três imagens de satélite: Landsat 5, sensor TM (Thematic Mapper) relativo aos anos de 1995 e 2005 e Landsat 8 sensor OLI (Operational Land Imager) relativo ao ano de 2014. Com o uso dos Softwares QGIS 2.8 e SPRING 4.3.3 foi realizado o processamento digital das imagens, formação de mosaicos, georreferenciamento e a classificação digital supervisionada, a partir da aquisição de amostras nas imagens. Foram definidas três classes de uso do solo do município: floresta, agricultura e campo. Para o período pesquisado, os resultados apontam uma significativa expansão agrícola e uma consequentemente retração das áreas de floresta e áreas de campo. No período de 1995 à 2014, as áreas agrícolas tiveram um aumento de 18,25\%, já as áreas de florestas tiveram uma supressão de 15,61\% e as áreas de campo um decréscimo de 2,61\%. Nesse sentido, destaca-se que as técnicas de sensoriamento remoto representam uma ferramenta muito útil para a realização de estudos com relação ao uso e cobertura do solo.
\end{abstract}

Palavras-chave: Uso do solo, Sensoriamento Remoto, Análise Espaço-temporal.

\begin{abstract}
The present study aimed to analyze changes in land use and land cover from Landsat images to check the expansion or contraction in the agricultural town of Centenário, RS, in the 1995-2014 period. Three satellite images were used: Landsat 5 TM sensor (Thematic Mapper) for the years 1995 and 2005 and Landsat 8 OLI sensor (Operational Land Imager) for the year 2014. Using the Softwares QGIS 2.8, SPRING 4.3.3 was done processing digital images, forming mosaics, georeferencing and supervised digital classification, from the acquisition of samples in the images. They were set three land use classes of the municipality: forestry, agriculture and countryside. For the period surveyed, the results indicate a significant agricultural expansion and consequently decrease the areas of forest and field areas. From 1995 to 2014, agricultural areas increased by 18.25\%, as forest areas have a suppression of $15.61 \%$ and the field areas a decrease of $2.61 \%$. In this sense, it is emphasized that remote sensing techniques are a useful tool for carrying out studies regarding the use and land cover.
\end{abstract}

Keywords: Use soil, Remote Sensing, Space- temporal analysis. 


\section{Introdução}

Ao estudar a dinâmica do uso do solo em uma determinada área é necessário entender os impactos provocados pela ação antrópica e as mudanças na cobertura do solo. Dentre os muitos impactos, destacam-se as ocorridas na dinâmica fluvial, alterando a diminuição da capacidade de infiltração e a diminuição da profundidade do leito dos cursos d'água (WENDLAND, 2001).

A expansão das atividades do setor agrícola, relacionado à monocultura, foi um dos fatores que contribuiram para as mudanças no uso e cobertura do solo no Brasil. "As chamadas "fronteiras agrícolas" estão entre estas mudanças e se apresentam entre as maiores fontes que incrementaram o desmatamento, transformando áreas nativas em espaço de cultivo agrícola e pecuário" (TORRES, 2011, p. 16).

Ao longo das décadas de 1990, 2000 e 2010 alterações na paisagem tornaram-se perceptíveis no município de Centenário-RS e, neste sentido, a análise multitemporal de imagens de satélites podem contribuir para a compreensão da evolução e mudança no uso e cobertura do solo.

Através desse tipo de análise é possivel caracterizar os atributos sócio-ambientais, bem como avaliar as áreas com uso agrícola, além de possíveis implicações ambientais provocados pelo uso.

Nesse sentido, o estudo do uso do solo constitui-se uma importante forma de compreender as relações entre o homem e a natureza, permitindo assim, definir ações que integrem o planejamento territorial e a gestão ambiental (OKA-FIORI et al., 2003). Ainda segundo os autores, o desenvolvimento das tecnologias possibilita importantes análises para os estudos da cobertura do solo.

De acordo com Florenzano (2011), o uso de imagens de satélite possibilita o estudo e monitoramento, tanto de fenômenos naturais do meio ambiente (erosão do solo, inundações etc) como impactos antrópicos, como por exemplo, a retirada da cobertura vegetal nativa para dar espaço à agricultura.

O Sensoriamento Remoto e o Geoprocessamento aparecem como técnicas auxiliares na obtenção e análise das informações espaciais (OKA-FIORI et al., 2003), por permitir o estudo do uso e cobertura do solo. Assim, com o registro destes processos nas imagens, obtidas pelo Sensoriamento Remoto e a análise multitemporal destas, é possível identificar e calcular as mudanças ocorridas na área de estudo.

Santos (2003) destaca que ao caracterizar o uso e cobertura do solo em séries temporais, quando bem espacializadas e avaliadas, constitui uma boa forma de análise das mudanças ocorridas, visando assim, um contínuo monitoramento das alterações que ocorrem na paisagem, sejam elas motivadas por causas naturais ou antrópicas.

Nesse contexto, torna-se relevante os estudos da paisagem e a caracterização das mudanças do uso e da cobertura do solo para a área rural do município de Centenário, RS. Pois, no município não existem estudos desta natureza. Assim, o referido estudo contribuirá na elaboração de um banco de dados do município que possa ser utilizados pelos gestores públicos no planejamento e gerenciamento de projetos futuros sobre a área em estudo.

\section{Objetivos Objetivo Geral}

Analisar as mudanças no uso e cobertura do solo, com as transformações da paisagem a partir de imagens Landsat 5 e 8, no município de Centenário, RS, nos anos de 1995, 2005 e 2014.

\subsubsection{Objetivos específicos}

1. Identificar o uso e cobertura do solo no município de Centenário, RS, utilizando imagens de satélite Landsat;

2. Avaliar a expansão e/ou retração das áreas de agricultura no município;

3. Relacionar as mudanças do uso e cobertura do solo com as transformações da paisagem na referida área de estudo.

\section{Metodologia}

\section{1 Área de estudo}

O município de Centenário, RS possui uma área de aproximadamente de $134,3 \mathrm{~km}^{2}$. Situa-se entre as coordenadas geográficas: -270 46 35' Latitude Sul - 520 01' $11^{\prime \prime}$ Longitude Oeste (Figura 1).

Localizado ao norte do Estado do Rio Grande do Sul, está inserido na microrregião geográfica de Erechim, RS, onde faz parte da Bacia Hidrográfica Apuaê-Inhandava. Esta tem como base o Rio Uruguai e pertence à Região Hidrográfica do Rio Uruguai.

\subsection{Abordagem Metodológica 2.2.1 Dados cartográficos e orbitais}

Para a realização do estudo, foram utilizados os seguintes materiais:

- Imagens Landsat 5, dos anos de 1995 e 2005 e imagem Landsat 8 do ano de 2014 (tabela 1). Imagens estas, adquiridas no site do Serviço de Levantamento Geológico Americano (USGS, 2013).

- As bases cartográficas do Rio Grande do Sul, foram obtidas através do site do Instituto Brasileiro de Geografia Estatística (IBGE, 2014).

A série temporal de imagens de satélites selecionadas para o desenvolvimento do trabalho foi de acordo com 


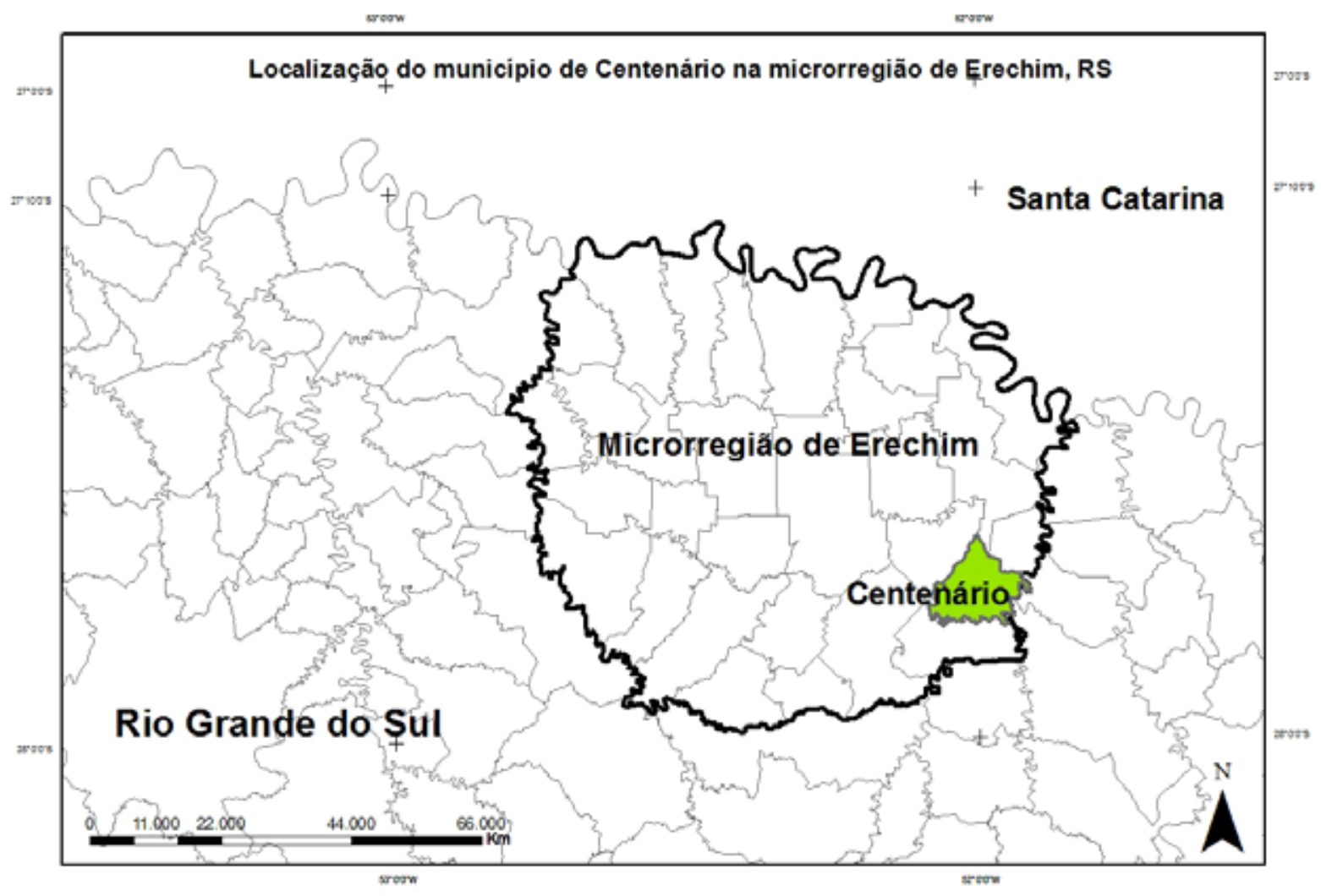

Figura 1 - Localização da área de estudo, município de Centenário, RS

Tabela 1 - Imagens de satélites Landsat utilizadas no trabalho

\begin{tabular}{c|c|c|c|c}
\hline Data & Satélite & Sensor & Órbita Ponto & Resolução Espacial \\
\hline $08 / 11 / 1995$ & Landsat 5 & TM & $222-79$ & $30 \mathrm{~m}$ \\
\hline $03 / 11 / 2005$ & Landsat 5 & TM & $222-79$ & $30 \mathrm{~m}$ \\
\hline $14 / 12 / 2014$ & Landsat 8 & OLI & $222-79$ & $30 \mathrm{~m}$ \\
\hline
\end{tabular}

Fonte: Levantamento Geológico Americano (USGS), 2013

a emancipação do município, em 20 de maço de 1992 e conforme a disponibilidade de imagens de boa qualidade, sem cobertura de nuvens e imagens do mesmo período (novembro e dezembro) tendo em vista o calendário agrícola, nesse período, é cultivada principalmente as culturas de milho e soja.

\subsubsection{Procedimentos metodológicos}

Para o desenvolvimento do trabalho, inicialmente foi realizada uma revisão bibliográfica, com leituras de artigos e livros contemplando a análise do uso e cobertura do solo, transformação da paisagem, modernização agrícola, assim como conceituação e aplicação do sensoriamento e SIG no mapeamento e análise do uso e cobertura do solo.

Na sequência, foram definidos os materiais utilizados.
Nessa etapa, selecionaram-se as imagens de satélite Landsat dos anos de 1995, 2005 e 2014, obtidas por meio do Serviço de Levantamento Geológico Americano (USGS).

A base cartográfica do Estado do Rio Grande do Sul, a rede hidroviária, a rede rodoviária e a área urbana do município de Centenário foram obtidas através do site do IBGE.

$\mathrm{Na}$ etapa posterior efetuou-se o georreferenciamento e o registro das imagens de satélite, no software QGIS 2.8 e SPRING 4.3.3, usando como referência o polígono do município de Centenário extraído da base cartográfica do Estado do Rio Grande do Sul. Para uma melhor visualização e interpretação das imagens utilizou-se da composição colorida. Esta composição foi associada às bandas 5 , 4 e 3 aos canais R, G e B no qual, segundo Moreira 2011, "é baseado nas cores vermelha (Red), 
verde (Green) e azul (Blue)" (p. 234).

A utilização de composições coloridas segundo Rosa (1992) é fundamental, uma vez que o olho humano consegue discriminar mais facilmente matrizes de cores do que tons de cinza, e assim, associar as cores às bandas permitindo uma melhora na diferenciação de alvos das imagens.

Para o refinamento das imagens utilizou-se a técnica de ampliação linear de contraste, buscando-se assim, melhorar a qualidade visual e destacar as feições que interessavam ao trabalho. Dessa maneira, a coleta de amostras de treinamento na etapa de classificação das imagens foi facilitada.

A etapa de classificação das imagens Landsat foi realizada em dois momentos: o treinamento e a classificação digital. Na etapa de treinamento, foi realizada a seleção de amostras de pixels da imagem com o intuito de identificar as classes desejadas. Foram definidas 3 classes:

1. Agricultura: áreas destinadas ao cultivo;

2. Floresta: vegetação densa;

3. Campo: vegetação arbustiva, gramado.

Com a seleção das amostras na fase de treinamento foi produzido um conjunto de assinaturas espectrais ${ }^{1}$, que, foram utilizadas como base para a classificação efetiva das imagens.

Para este trabalho foi utilizada a classificação digital supervisionada, onde o analista fornece amostras das categorias pertinentes ao foco do trabalho que está sendo realizado. De acordo com Novo (2008), a classificação supervisionada exige um conhecimento prévio sobre a área de estudo facilitando a identificação das áreas de treinamento sobre as imagens.

O classificador utilizado para o trabalho foi o de Máxima Verossimilhança (MaxVer), um algoritmo estatístico, que consiste em classificar pixel a pixel, a partir das classes fornecidas. De acordo com Reis, et al., (2011, p. 150), o método MaxVer, utilizando parâmetros estatísticos, implica em ponderar as distâncias médias dos níveis digitais das classes e, segundo Liu (2006) é considerado o método mais utilizado nos processos de identificar e delinear classes.

Posteriormente, por meio do mapeamento do uso e cobertura do solo foram elaborados os mapas temáticos para três períodos distintos, 1995, 2005 e 2014. As imagens classificadas foram transformadas em vetores do tipo poligonal, com o objetivo de obter o resultado da área dos polígonos de cada classe. Após, os vetores foram unidos, no qual permitiu a formação de mapas temáticos para toda área do município e também foram geradas tabelas que continham informações das áreas dos polígonos para cada classe.

Os dados foram exportados em tabela do Excel, com o objetivo de formatar os resultados dos dados e formatar as tabelas finais. Nos mapas de uso e cobertura do solo referente a 1995, 2005 e 2014 foram inseridas as

1 Assinatura espectral é o comportamento de refletância de um objeto para cada comprimento de onda (NOVO, 2011). coordenadas geográficas, legenda, escala e orientação.

A partir da elaboração dos mapas referentes aos anos de 1995, 2005 e 2014 foi constatada as alterações no uso do solo do município de Centenário, RS. Isso se deu a partir da sobreposição dos mapas. Assim, foi gerado o mapa da expansão das áreas agrícolas no município de Centenário de 1995 à 2014.

A partir dos resultados do mapeamento das classes de uso e cobertura do solo, iniciou-se a análise dos resultados, buscando analisar a expansão ou retração das áreas agrícolas.

\section{Resultados}

A apresentação dos resultados está organizada em 3 partes. Inicialmente realizou-se a análise do uso do solo do município de Centenário, RS para os períodos de 08/11/1995, 03/11/2005 e 14/12/2014; seguida da análise da expansão ou retração das áreas agrícolas no município de Centenário, RS e, por fim, relacionou-se as mudanças do uso e cobertura do solo com as transformações da paisagem.

\subsection{Uso do solo}

\subsubsection{Uso do solo no ano de 1995}

$\mathrm{O}$ resultado do mapeamento do uso do solo no município de Centenário, a partir da imagem de satélite Landsat 5 , sensor TM, orbita e ponto 222/079, tomados em 08/11/1995, corresponde a figura 2. A tabela 2 apresenta as áreas em $\mathrm{km}^{2}$ e os percentuais das três classes do mapeamento.

Tabela 2 - Quantificação das classes do uso do solo, Centenário, RS - 1995

\begin{tabular}{c|c|c}
\hline Classes & Área $\mathbf{( k m}^{\mathbf{2}}$ & $\mathbf{\%}$ \\
\hline Floresta & 51,55 & 38,38 \\
\hline Agricultura & 78,30 & 58,29 \\
\hline Campos & 4,47 & 3,33 \\
\hline Totais & 134,33 & 100 \\
\hline
\end{tabular}

A análise dos resultados apresentados na tabela 2 e no mapa do uso do solo (figura 2) demonstram que as áreas agrícolas em 1995, já ocupavam uma área de $78,30 \mathrm{~km}^{2}$, $(58,29 \%)$ da área do município, as áreas de florestas ocupavam uma área expressiva $51,55 \mathrm{~km}^{2},(38,38 \%)$ e as áreas de campos ocupavam uma área de $4,47 \mathrm{~km}^{2}$, $(3,33 \%)$ totalizando os $100 \%$ da área do município.

A partir do mapa, e levando em consideração a distribuição das classes, verifica-se que, a concentração 


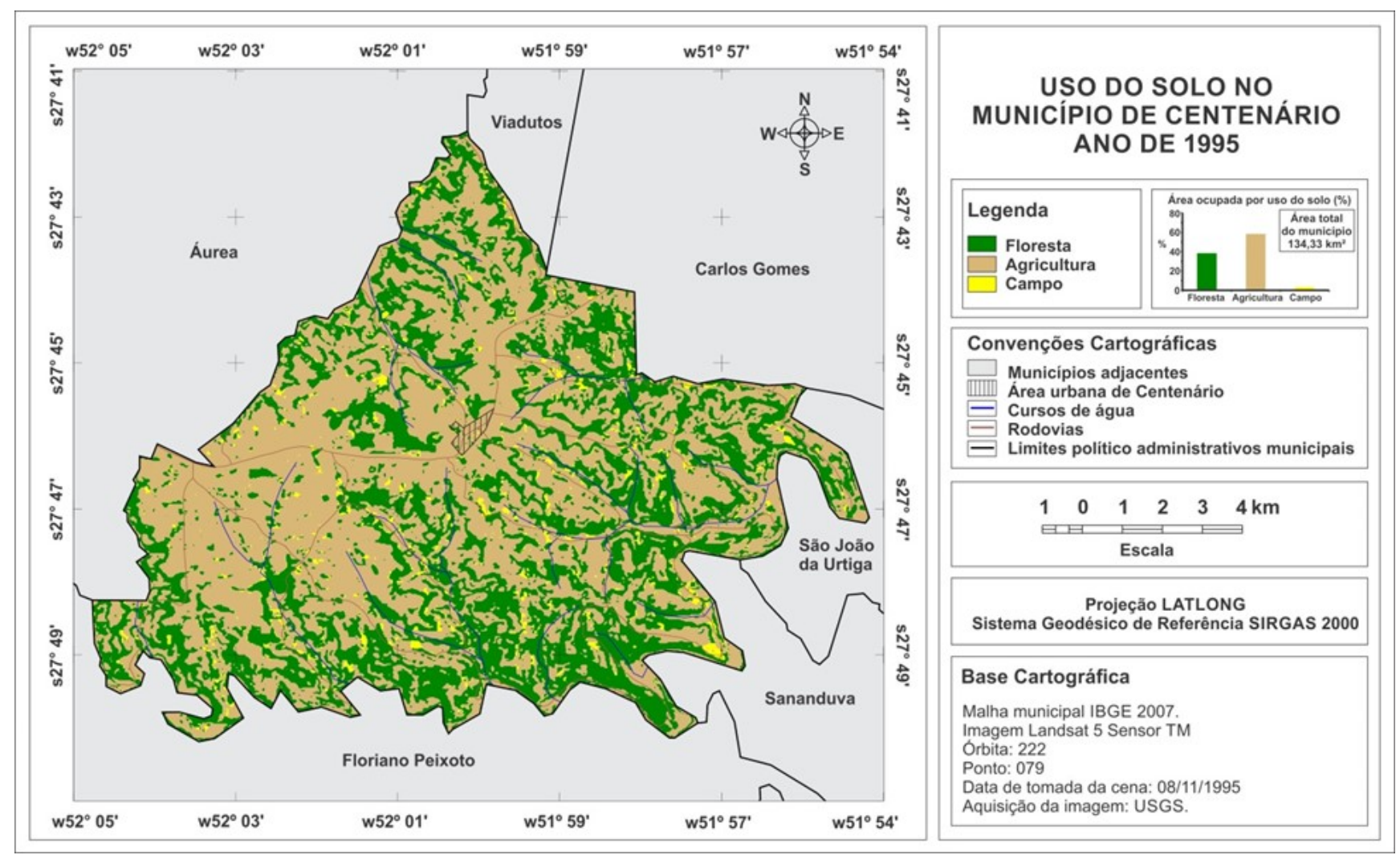

Figura 2 - Mapa do uso do solo, Centenário, RS, 1995

Fonte: May; Reis, 2015

das áreas agrícolas e campos estão no alto e baixo curso dos rios e nas áreas de várzea dos rios, evidenciando-se assim, que o cultivo agrícola se desenvolve nas áreas com topografia mais plana, característica que favorece a mecanização da produção e maior produtividade.

Já a classe de florestas concentra-se no médio curso dos rios, nas encostas

dos morros com declive acentuado. Destacando assim, que devido a topografia mais íngreme, se enfrenta dificuldades para o cultivo agrícola.

\subsubsection{Uso do solo no ano de 2005}

Os dados oriundos do mapeamento do uso e cobertura do solo no município, a partir da imagem de satélite Landsat 5, sensor TM, orbita e ponto 222/079, tomados em 03/11/2005, podem ser observados na figura 3 e tabela 3 . Assim, a tabela 3 apresenta as áreas em $\mathrm{km}^{2}$ e os percentuais das três classes mapeadas

As áreas de florestas tiveram uma relevante diminuição neste período, principalmente nas áreas á montante das nascentes, passando de $51,55 \mathrm{~km}^{2}(38,38 \%)$ para $32,95 \mathrm{~km}^{2}(24,53 \%)$, uma perda florestal de 18,60 $\mathrm{km}^{2}(13,85 \%)$.

Os campos também tiveram uma diminuição de área, passando de $4,47 \mathrm{~km}^{2}(3,33 \%)$ para uma área de $2,96 \mathrm{~km}^{2}(2,21 \%)$, ou seja, uma diminuição de $1,51 \mathrm{~km}^{2}$ $(1,12 \%)$. Tal fato foi causado pela expansão das áreas agrícolas, destacando-se os cultivos de soja e milho, pois, neste período tiveram um significativo aumento (14,97\%), passando de uma área de $78,30 \mathrm{~km}^{2}$ para uma área de $98,41 \mathrm{~km}^{2}$, ou seja, um aumento de $20,11 \mathrm{~km}^{2}$.

A análise do uso do solo de 2005 (figura 3) destaca, que as áreas agrícolas que predominavam nas áreas mais planas e várzeas (1995), uma década após (2005), estavam em um processo de expansão para as áreas mais íngremes, no médio curso dos rios, evidenciando-se assim, uma intensa alteração na paisagem, no qual, a cobertura vegetal é retirada e as atividades agrícolas se expandem.

Tabela 3 - Quantificação das classes do uso do solo, Centenário, RS - 2005

\begin{tabular}{l|c|c}
\hline Classes & Área $\left.\mathbf{( k m}^{\mathbf{2}}\right)$ & $\mathbf{\%}$ \\
\hline Floresta & 32,95 & 24,53 \\
\hline Agricultura & 98,41 & 73,26 \\
\hline Campos & 2,96 & 2,21 \\
\hline Totais & 134,33 & 100 \\
\hline
\end{tabular}

\subsubsection{Uso do solo no ano de 2014}

O uso e cobertura do solo mapeados no município 


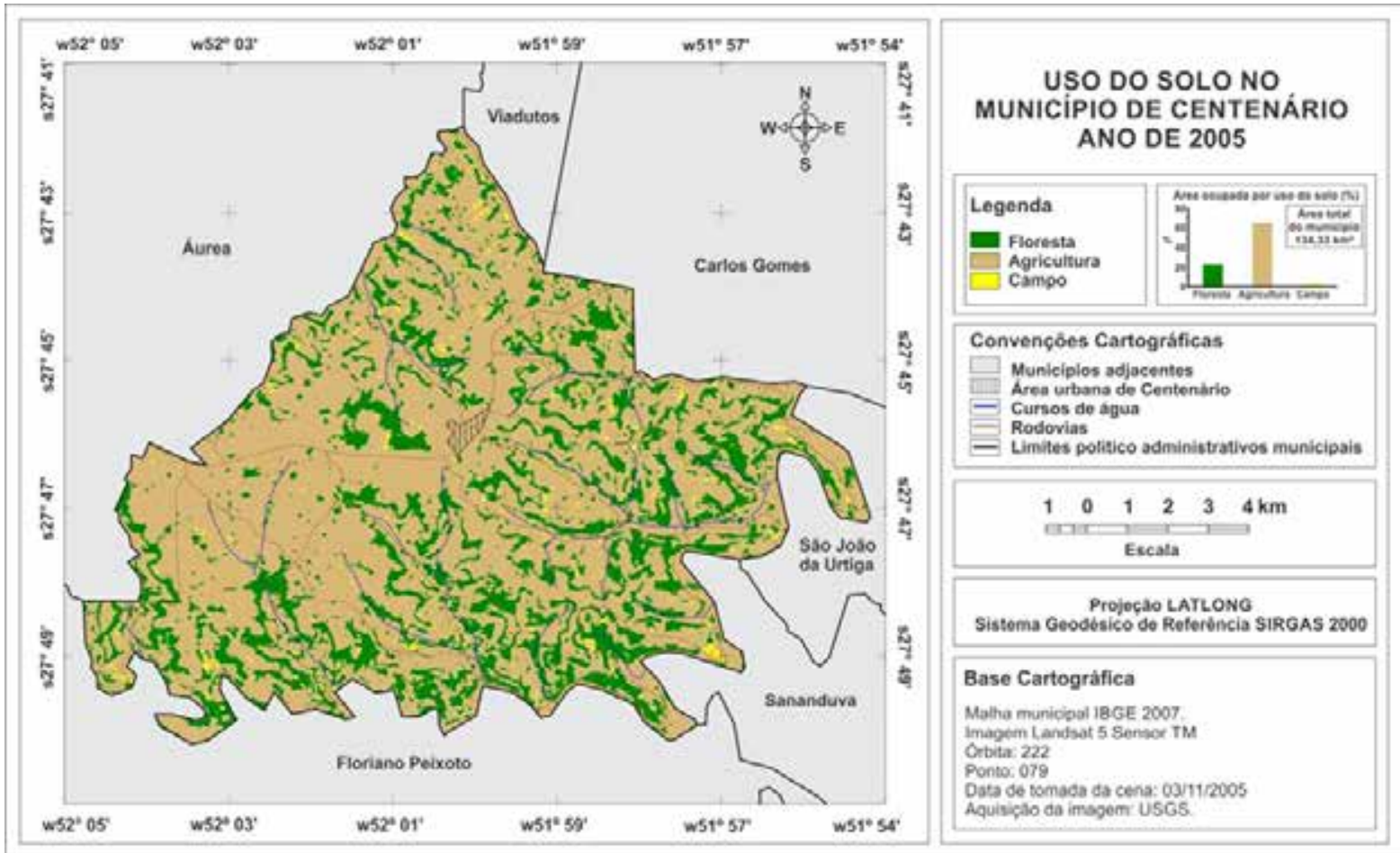

Figura 3 - Mapa do uso do solo, Centenário, RS, 2005

Fonte: May; Reis, 2015

de Centenário, a partir da imagem de satélite Landsat 8 , sensor OLI, órbita e ponto $222 / 079$, tomados em $14 / 12 / 2014$, podem ser visualizados na figura 4 . Já a tabela 4 apresenta as áreas em $\mathrm{km}^{2}$ e os percentuais das três classes do mapeamento.

Por meio da análise do uso do solo de 2014 (figura
4) e dos dados da tabela 4, ratifica-se o aumento das áreas agrícolas no município e a consecutiva retração das áreas de florestas e de campos. Através destes, foi possível verificar que as áreas de florestas tiveram mais uma diminuição neste período, de $32,95 \mathrm{~km}^{2}(24,53 \%)$ em 2005 , para $30,58 \mathrm{~km}^{2}(22,77 \%)$ em 2014 , uma perda

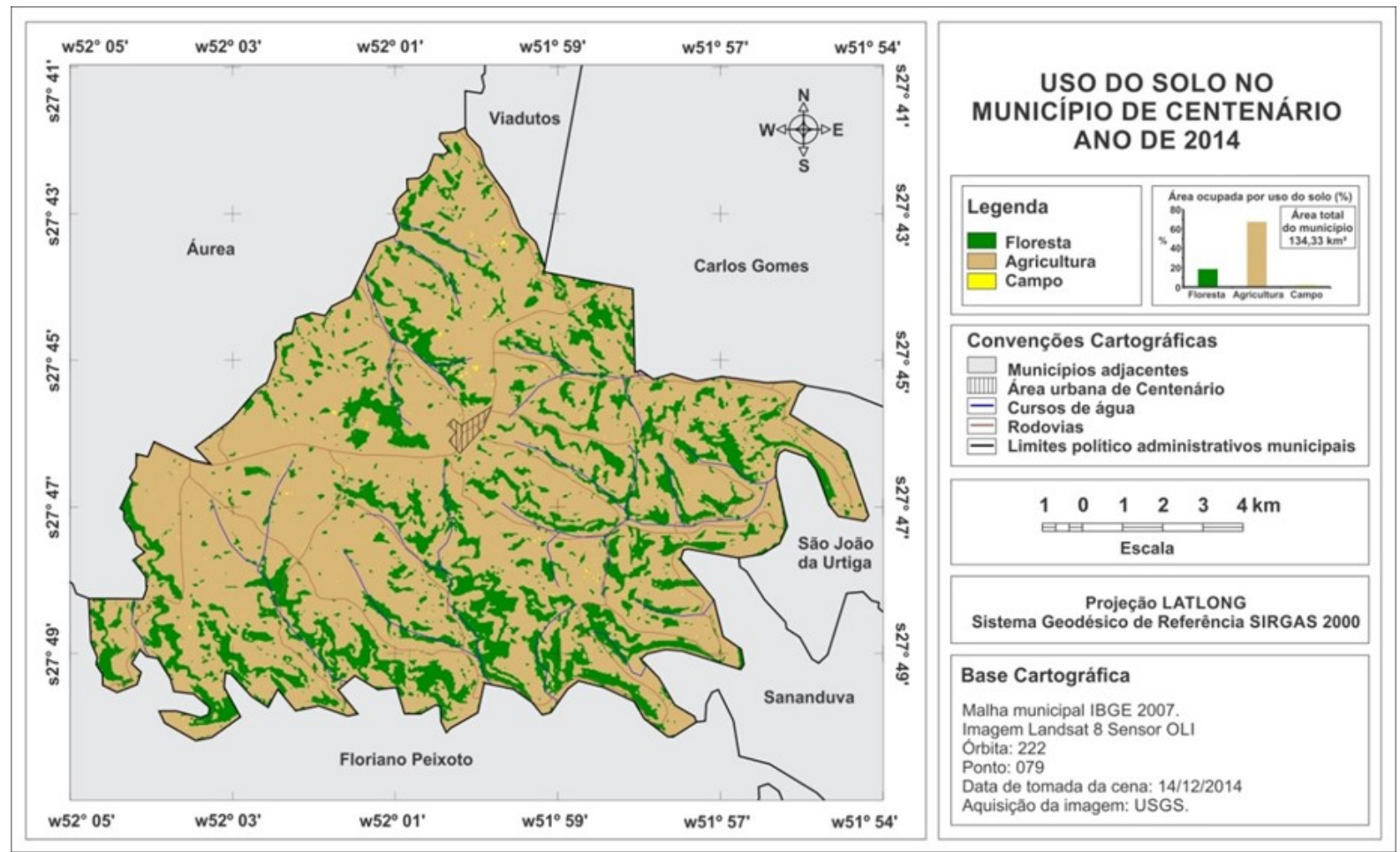

Figura 4: Mapa do uso do solo, Centenário, RS, 2014.

Fonte: May; Reis, 2015 
Tabela 4 - Quantificação das classes do uso e cobertura do solo, Centenário, RS - 2014

\begin{tabular}{c|c|c}
\hline Classes & Área $\left(\mathbf{K m}^{\mathbf{2}}\right)$ & $\mathbf{\%}$ \\
\hline Floresta & 30,585 & 22,77 \\
\hline Agricultura & 102,816 & 76,54 \\
\hline Campos & 0,93 & 0,69 \\
\hline Totais & 134,331 & 100 \\
\hline
\end{tabular}

de 2,36 km² (1,76\%) de florestas.

As áreas de campo também tiveram uma queda em relação ao ano de 2005, passaram de 2,96 km² (2,21\%),

para uma área em 2014 de $0,93 \mathrm{~km}^{2}(0,69 \%)$, ou seja, uma diminuição de $2,03 \mathrm{~km}^{2}(1,52 \%)$.

As áreas agrícolas, assim, como na década de 1995/2005, neste período, também aumentaram (3,28\%), de uma área de $98,41 \mathrm{~km}^{2}$ (2005), para $102,81 \mathrm{~km}^{2}$, um aumento de $4,40 \mathrm{~km}^{2}$. Ressalta-se, portanto, que os principais cultivos agrícolas do município são: soja, milho, trigo, e a criação de gado leiteiro.

Observa-se, que as áreas agrícolas expandiram-se praticamente por todo território do município, apenas nas áreas com topografia íngremes com vales encaixados e em algumas áreas de preservação permanente - APPs (com relevo íngreme) não foi retirada a vegetação, para dar espaço à agricultura.

\subsubsection{Alterações do uso do solo entre os anos de 1995,2005 e 2014}

A análise das mudanças espaço-temporais do uso do solo no município de Centenário, RS, no período estudado, (1995, 2005 e 2014). Foi verificada a variação percentual das áreas em $\mathrm{km}^{2}$, conforme tabela 5 .

Analisando os resultados da tabela 5, com os dados quantitativos referentes as classes de uso do solo dos anos pesquisados (1995, 2005 e 2014), destaca-se que as áreas de floresta e campo tiveram significativa retração, dando espaço para as áreas agrícolas, representando assim, uma mudança no uso do solo do município de Centenário neste período.

Pode-se destacar que as áreas de florestas tiveram uma redução de $15,61 \%$, permanecendo principalmente em áreas íngremes e nos fundos de vales, no qual ainda maquinários agrícolas não podem chegar.

As áreas de campos também tiveram uma redução de 2,64\%. A agricultura foi a única classe que teve uma expressiva expansão, passando de $78,30 \mathrm{~km}^{2}$ (58,29\%), em 1995, para $102,81 \mathrm{~km}^{2}(76,54 \%)$ em 2014 , um aumento de $18,25 \%$.

\subsubsection{Expansão das áreas de agricultura no municí- pio de Centenário, RS}

A integração dos mapas dos três anos estudados permitiu espacializar a expansão das áreas agrícolas. A figura 5 mostra de forma qualitativa, a expansão das áreas agrícolas no município de Centenário (1995-2014). A tabela 6 demonstra a variação positiva das áreas agrícolas no período.

De acordo com a tabela 6 e a figura 5, as áreas destinadas para a agricultura nos últimos anos tiveram e encontram-se em um cenário de expansão, visto que, nos intervalos analisados (1995, 2005 e 2014), as áreas agrícolas produtoras de grãos (agricultura temporária) expandiram a cada data investigada com um aumento de $18,25 \%\left(24,51 \mathrm{~km}^{2}\right)$.

Destaca-se que, o forte crescimento ocorreu principalmente, nos anos de 1995 a 2005 com um aumento de $14,97 \%\left(20,11 \mathrm{~km}^{2}\right)$ e um dos principais fatores dessa mudança foi o avanço das áreas agrícolas sobre as áreas de florestas e campos.

Este avanço também pode ser observado nos dados dos censos agropecuários (IBGE): 1995/96 e 2006, onde a agricultura temporária teve um aumento significativo de área.

De acordo com o censo agropecuário (1995/1996),

Tabela5: Alterações do uso do solo do município de Centenário, RS, entre 1995 - 2014.

\begin{tabular}{|c|c|c|c|c|c|c|c|}
\hline \multirow{2}{*}{$\begin{array}{l}\text { Classes de } \\
\text { uso do solo }\end{array}$} & \multicolumn{2}{|c|}{1995} & \multicolumn{2}{|c|}{2005} & \multicolumn{2}{|c|}{2014} & \multirow{2}{*}{$\begin{array}{l}\text { Alterações (\%) do } \\
\text { uso do solo } \\
1995 \text { - } 2014\end{array}$} \\
\hline & $\begin{array}{l}\text { Área } \\
\left(\mathrm{Km}^{2}\right)\end{array}$ & $\%$ & $\begin{array}{l}\text { Área } \\
\left(\mathrm{km}^{2}\right)\end{array}$ & $\%$ & $\begin{array}{l}\text { Área } \\
\left(\mathrm{km}^{2}\right)\end{array}$ & $\%$ & \\
\hline Floresta & 51,555 & 38,38 & 32,953 & 24,53 & 30,585 & 22,77 & $-15,61$ \\
\hline Agricultura & 78,301 & 58,29 & 98,416 & 73,26 & 102,816 & 76,54 & $+18,25$ \\
\hline Campos & 4,475 & 3,33 & 2,962 & 2,21 & 0,93 & 0,69 & $-2,64$ \\
\hline Totais & 134,331 & 100 & 134,331 & 100 & 134,331 & 100 & -...-..... \\
\hline
\end{tabular}




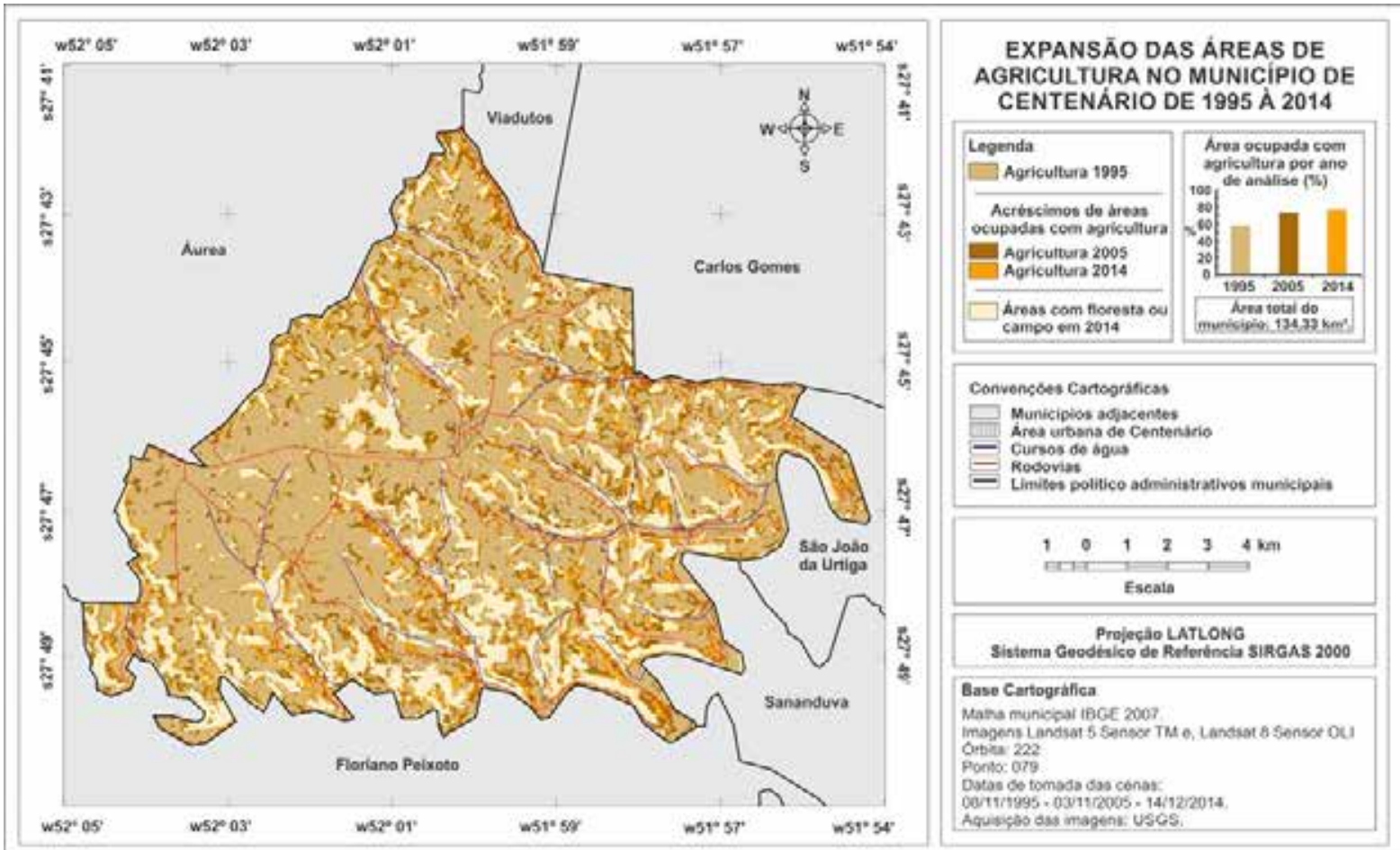

Figura 5 - Mapa da expansão das áreas de agricultura no município de Centenário de 1995 à 2014 Fonte: May; Reis, 2015

Tabela 6 - Expansão das áreas de agricultura no município de Centenário, RS no período de 1995-2014

\begin{tabular}{|c|c|c|c|c|c|c|c|}
\hline \multirow{2}{*}{$\begin{array}{l}\text { Classe do uso } \\
\text { do solo }\end{array}$} & \multicolumn{2}{|c|}{1995} & \multicolumn{2}{|c|}{2005} & \multicolumn{2}{|c|}{2014} & \multirow{2}{*}{$\begin{array}{c}\text { Expansão }(\%) \text { das } \\
\text { áreas agrícolas } \\
1995-2014\end{array}$} \\
\hline & $\begin{array}{l}\text { Área } \\
\left(\mathrm{km}^{2}\right)\end{array}$ & $\%$ & $\begin{array}{l}\text { Área } \\
\left(\mathbf{k m}^{2}\right)\end{array}$ & $\%$ & $\begin{array}{l}\text { Área } \\
\left(\mathbf{k m}^{2}\right)\end{array}$ & $\%$ & \\
\hline Agricultura & 78,30 & 58,29 & 98,41 & 73,26 & 102,81 & 76,54 & $+18,25$ \\
\hline Totais & 134,33 & 100 & 134,33 & 100 & 134,33 & 100 & ---------- \\
\hline
\end{tabular}

levando em conta o calendário agrícola, nesse período, com o cultivo principalmente de soja e milho, destaca-se que a área com o cultivo de soja era de 2500 hectares, ou seja, $25 \mathrm{~km}^{2}$, e a área com o cultivo de milho era de 4600 hectares $\left(46 \mathrm{~km}^{2}\right)$. Somando-se as duas principais culturas destaca-se que a área total era de 7100 hectares $\left(71 \mathrm{~km}^{2}\right)$.

Analisando o censo agropecuário de 2006, destacase que as áreas destinadas ao cultivo de soja e milho aumentaram. As áreas para o cultivo de soja passaram de 2500 hectares $\left(25 \mathrm{~km}^{2}\right)$ em 1996 para 5200 hectares em $2006\left(52 \mathrm{~km}^{2}\right)$, ou seja, um aumento de 2700 hectares $\left(27 \mathrm{~km}^{2}\right)$. Já a cultura de milho teve um decréscimo, passando de 4600 hectares $\left(46 \mathrm{~km}^{2}\right)$ em 1996 para uma área de 3300 hectares, $\left(33 \mathrm{~km}^{2}\right)$, ou seja, uma diminuição de 1300 hectares $\left(13 \mathrm{~km}^{2}\right)$.

Somando as duas culturas (milho, soja) destaca-se que houve um aumento significativo em relação ao censo anterior já que no censo agropecuário de 1995/1996, elas somavam uma área de 7100 hectares $\left(71 \mathrm{~km}^{2}\right)$ e no censo de 2006, somam 8500 hectares $\left(85 \mathrm{~km}^{2}\right)$, perfazendo um aumento de 1400 hectares $\left(14 \mathrm{~km}^{2}\right)$, destacando assim, a expansão da agricultura sobre as áreas de campo e floresta.

\subsection{Mudanças do uso e cobertura do solo e as transformações da paisagem no município de Centenário}

Através das análises dos resultados dos mapas, podese observar que ao longo dos últimos anos as mudanças no uso e cobertura do solo têm provocado alterações significativas na paisagem do município de Centenário.

Com a modernização da agricultura, os agricultores foram forçados a substituir seus equipamentos de trabalho e os seus métodos de cultivo, rompendo com o cultivo de subsistência. Assim, passaram a trabalhar 
com equipamentos cada vez mais modernos, com o uso de insumos químicos e monocultivo, transformando em uma agricultura antiecológica e direcionada ao mercado.

Destaca-se, o avanço das áreas agrícolas em direção as áreas de florestas. Um dos fatores que contribuiu para essa expansão foi o acesso dos agricultores aos créditos rurais para a compra de pacotes tecnológicos (sementes híbridas, agrotóxicos e máquinas agrícolas).

No município, se destaca a partir da década de 1990 o acesso ao Programa Nacional de Fortalecimento da Agricultura Familiar (Pronaf), um programa de apoio econômico e produtivo à agricultura familiar, visando integrar as ações governamentais para este segmento social (GAZZOLA; SCHNEIDER, 2013). Com esse acesso, os agricultores com a possibilidade de aumentar sua renda agrícola passaram a utilizar as novas práticas de produção e manuseio de solo, adquirindo dívidas nos bancos, e pouca área para o cultivo, tiveram que expandir as áreas, desencadeando o desmatamento das áreas de florestas.

Do ponto de vista do meio ambiente a mecanização da agricultura intensifica a derrubada da vegetação. Assim, cada vez mais os agricultores contratam proprietários de tratores esteiras para retirar a vegetação e transformar em áreas agrícolas.

A mecanização agrícola traz ao meio ambiente, inúmeros impactos negativos, pois, visando aumentar a produção agrícola para pagar os custos, o agricultor é forçado expandir sua área de cultivo, não se preocupando com a degradação do meio ambiente e o manejo adequado do solo, agravando assim os problemas ambientais acarretando impactos negativos ao meio ambiente.

Nesse contexto, destaca-se que a paisagem do município de Centenário, RS, ao longo dos anos foi se transformando, caracterizado por uma forte expansão das áreas agrícolas em detrimento das áreas de florestas, que estão bem reduzidas restando ainda algumas pequenas áreas de campos. Assim, ressalta-se que a intensa alteração na cobertura do solo evidência os conflitos entre o uso do solo e a preservação das florestas.

\section{Conclusões}

O presente trabalho objetivou analisar as mudanças no uso e cobertura do solo, a partir de imagens Landsat, para verificar a expansão ou retração agrícola no município de Centenário, RS, nos anos de 1995, 2005 e 2014.

Com a utilização de imagens de satélites Landsat o presente estudo possibilitou determinar o uso e cobertura do solo no município, avaliar a expansão e/ou retração das áreas agrícolas e relacionar as mudanças do uso e cobertura do solo com as transformações da paisagem.

A utilização de imagens de satélites aliada ao geoprocessamento, mostrou-se eficiente no mapeamento do uso do solo. Evidencia-se a importância do Sensoriamento
Remoto para as análises das mudanças no uso e cobertura do solo, pois, permite reconstituir uma determinada área, que foi alterada em determinado período de tempo, e assim, poder compreender a dinâmica da paisagem. Desse modo, a geração dos mapas temáticos do uso do solo, associados à revisão bibliográfica possibilitaram a análise da paisagem do município.

Por meio da análise espaço-temporal pode-se constatar que a agricultura expandiu em todos os anos estudados. Apresentou uma expansão total de $18,25 \%$ da área do município, com destaque no período de 1995-2005, com um incremento de $14,97 \%$. No período posterior $2005-2014$ as áreas agrícolas continuaram se expandindo, porém em menor proporção, um aumento de 3,28\%. Enquanto as classes de florestas e campos apresentaram uma retração significativa de área a cada ano investigado. As áreas de florestas tiveram uma retração de $15,61 \%$ e as áreas de campo uma redução de 2,64\%.

Portanto, este estudo evidenciou que o uso do solo oriundo das atividades agrícolas tem modificado a paisagem e vem trazendo impacto negativo na conservação das áreas de florestas. Cabe, porém, uma investigação mais precisa quanto às áreas de conflito do uso do solo para propor medidas mitigadoras objetivando a conservação das áreas de florestas no município e uma possível reposição das áreas em conflito.

\section{Agradecimentos}

Agradecimentos a revisores, colaboradores e agências de fomento.

\section{Referências}

FLORENZANO, T. G. Iniciação ao Sensoriamento Remoto. 3 ed. São Paulo: Oficina de Textos, 2011.

GAZOLLA, M.; SCHNEIDER, S. Qual "Fortalecimento" da Agricultura Familiar? Uma análise do Pronaf crédito de custeio e investimento no Rio Grande do Sul. Revista de Economia e Sociologia Rural (ESR), Piracicaba-SP, Vol. 51, № 1, p. 045-068, Jan/Mar 2013.

BRASIL. 1995/96.Censo Agropecuário. Disponível em: <http;//www.ibge.gov.br.htm>. Acesso em: 25/07/2015.

BRASIL. 2006. Censo Agropecuário. Disponível em: <http;//www.ibge.gov.br.htm>. Acesso em: 25/07/2015.

IBGE. Geociências: Camadas vetoriais. 2014. Disponível em: www.sidra.ibge.gov.br.

LIU, W. T. Aplicações em Sensoriamento Remoto. Campo Grande: UNIDERP. 2006. 
MOREIRA, M. A. Fundamentos do Sensoriamento Remoto e Metodologias de Aplicação. 4. ed. Viçosa: UFV, 2011.

NOVO, E. M. L. M. Sensoriamento Remoto: Princípios e Aplicações. $4^{a}$ ed. São Paulo: Edgard Blücher, 2008. 387p.

OKA-FIORI, C.; FIORI, A. P.; HASUI, Y. Dinâmica da ocupação do solo na bacia do Rio Itiquira, Mato Grosso, Brasil. Revista RA'E GA, Curitiba, n. 7, 2003. p. 19-31.

REIS, J. T.; FILHO, W.P.; SILVEIRA, A.L.L. Estimativa entre densidade habitacional e áreas impermeáveis na região urbana da sub-bacia hidrográfica do arroio Cadena em Santa Maria, RS. Ciência e Natura, UFSM, 33 (1): p. $145-160,2011$.

ROSA, R. Introdução ao Sensoriamento Remoto. Uberlândia - MG, editora da UFU (EDUFU), 1992. 109 p.
SANTOS M. A. Construção de cenários em ambiente SIG para avaliar mudanças de uso das terras induzidas por usinas hidrelétricas na região agrícola de Andradina [dissertação]. Campinas: Faculdade de Engenharia Agrícola, Universidade Estadual de Campinas; 2003.

TORRES D. R. Análise multitemporal do uso da terra e cobertura florestal com dados dos satélites LANDSAT e ALOS [dissertação]. Santa Maria: Centro de Ciências Rurais, Universidade Federal de Santa Maria; 2011.

USGS - Geological Survey / Serviço de Levantamento Geológico Americano (2013). Aquisição de imagens orbitais digitais gratuitas do satélite Landsat-8 EUA. Acesso em 16 de maio de 2015. Disponível em: http://landsat.usgs. gov/band_designations_landsat_satellites.php.

WENDLAND, W. M. Temporal responses of surface-water and ground-water to precipitation in Illinois, Journal of the American Water Research. V. 37, n 3, p. 685-693. 2001 